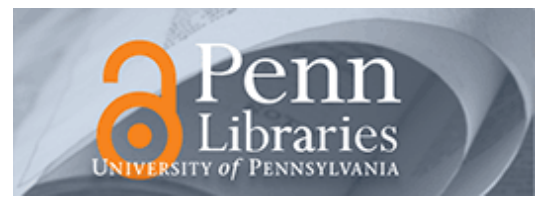

University of Pennsylvania

ScholarlyCommons

Accounting Papers

Wharton Faculty Research

3-2010

\title{
The Role of the Business Press as an Information Intermediary
}

Brian J. Bushee

University of Pennsylvania

John E. Core

University of Pennsylvania

Wayne R. Guay

University of Pennsylvania

Sophia J. W. Hamm

University of Pennsylvania

Follow this and additional works at: https://repository.upenn.edu/accounting_papers

Part of the Accounting Commons

\section{Recommended Citation}

Bushee, B. J., Core, J. E., Guay, W. R., \& Hamm, S. W. (2010). The Role of the Business Press as an Information Intermediary. Journal of Accounting Research, 48 (1), 1-19. http://dx.doi.org/10.1111/ j.1475-679X.2009.00357.x

This paper is posted at ScholarlyCommons. https://repository.upenn.edu/accounting_papers/44

For more information, please contact repository@pobox.upenn.edu. 


\title{
The Role of the Business Press as an Information Intermediary
}

\author{
Abstract \\ This paper investigates whether the business press serves as an information intermediary. The press \\ potentially shapes firms' information environments by packaging and disseminating information, as well \\ as by creating new information through journalism activities. We find that greater press coverage reduces \\ information asymmetry (i.e., lower spreads and greater depth) around earnings announcements, with \\ broad dissemination of information having a bigger impact than the quantity or quality of press-generated \\ information. These results are robust to controlling for firm-initiated disclosures, market reactions to the \\ announcement, and other information intermediaries. Our findings suggest that the press helps reduce \\ information problems around earnings announcements. \\ Disciplines \\ Accounting
}




\title{
The Role of the Business Press as an Information Intermediary
}

\author{
Brian J. Bushee \\ The Wharton School \\ University of Pennsylvania \\ 1300 Steinberg-Dietrich Hall \\ Philadelphia, PA 19104-6365 \\ bushee@wharton.upenn.edu
}

\author{
John E. Core \\ The Wharton School \\ University of Pennsylvania \\ 1300 Steinberg-Dietrich Hall \\ Philadelphia, PA 19104-6365 \\ jcore@wharton.upenn.edu \\ Wayne Guay \\ The Wharton School \\ University of Pennsylvania \\ 1300 Steinberg-Dietrich Hall \\ Philadelphia, PA 19104-6365 \\ guay@wharton.upenn.edu
}

Sophia J.W. Hamm

The Wharton School

University of Pennsylvania

1300 Steinberg-Dietrich Hall

Philadelphia, PA 19104-6365

jwee@wharton.upenn.edu

We would like to thank Haruhiko Fujiwara, Amy Gu, and Jing-Jing Wang for their research assistance. We appreciate the helpful comments of Richard Leftwich (editor), an anonymous reviewer, Catherine Schrand, Alexander Dyck, Gus DeFranco, Richard Frankel, Gordon Richardson, Scott Richardson, Rodrigo Verdi, Robert Verrecchia, and seminar participants at the University of Amsterdam, University of Chicago, Erasmus School of Economics, University of Michigan, University of Minnesota, New York University, Penn State University, University of Toronto, Washington University, and the Wharton School. We are grateful for the financial support of the Wharton School. 


\title{
The Role of the Business Press as an Information Intermediary
}

\begin{abstract}
This paper investigates whether the business press serves as an information intermediary. The press potentially shapes firms' information environments by packaging and disseminating information, as well as by creating new information through journalism activities. We find that greater press coverage reduces information asymmetry (i.e., lower spreads and greater depth) around earnings announcements, with broad dissemination of information having a bigger impact than the quantity or quality of press-generated information. These results are robust to controlling for firm-initiated disclosures, market reactions to the announcement, and other information intermediaries. Our findings suggest that the press helps reduce information problems around earnings announcements.
\end{abstract}




\section{Introduction}

We investigate whether the business press serves as an information intermediary in the capital markets. We use the term "information intermediary" to refer to an agent that provides information that is new and useful to other parties, either because it has not previously been publicly released or because it has not been widely disseminated. The business press is perhaps the broadest and most widely disseminated of all potential information intermediaries, reaching both sophisticated and unsophisticated investors, as well as managers, regulators, and other market participants. However, if the business press does not add new material information beyond the firm disclosure it disseminates and/or if its information does not reach a broader class of investors than that reached by other information intermediaries, such as analysts, then press coverage will not meaningfully enrich a firm's information environment. Thus, we examine whether the press influences a firm's information environment incremental to both firm-initiated disclosure and other intermediaries, such as financial analysts and institutional investors.

Specifically, we test whether press coverage influences the degree of information asymmetry around earnings announcements. The business press provides information to market participants through the timely dissemination of firm-initiated information to a broad investor base, as well as through the creation and packaging of new information. Through these activities, the press has the potential to reduce information asymmetry across investors, and thus, reduce bid-ask spreads and increase market depth. We focus on earnings announcements because they are well-defined information events that occur for all firms and they allow us to control for "normal" levels of pre-announcement press coverage and firm disclosure.

We examine press coverage for a sample of 27,987 firm-quarters of 1,182 medium-sized NASDAQ growth firms between 1993 and 2004. We select this sample because we wish to focus 
on firms that have sufficient cross-sectional variation in the quality of their information environments and capital needs, as well as variation in the intensity of press coverage. We collect data on 600,478 press articles from the Factiva database. We classify each of these articles as firm-initiated or press-initiated coverage based on the source of the article. This distinction is important to ensure that our press variables capture the impact of the media in creating and disseminating information, rather than the effects of the firms' own disclosure practices. Reflecting the multiple roles of the press, we examine four measures of press coverage: aggregate word count, number of sources covering the firm, amount of additional information packaged in the articles, and the presence of reporter-generated analysis.

Our results indicate that press coverage has a significant effect on firms' information asymmetry around earnings announcements. We find that greater press coverage during the earnings announcement window is associated with reductions in bid-ask spreads and improvements in depth. These results are robust to controlling for firm-initiated disclosures, the stock return and volume reaction to the earnings announcement, firm size, and the presence of other information intermediaries, such as analysts and institutional investors. Our results suggest that broad dissemination of information by the press has a bigger impact on information asymmetry than quantity or quality of information provided by the press. We also find that abnormal press coverage is associated with an increase in the number of small trades and block trades. These findings are consistent with a press-induced reduction in information asymmetry during the earnings announcement, presumably due to attenuation of the information advantage of privately-informed investors and/or to reduced incentives of investors to acquire private information. 
In developing our control variables for this analysis, we present descriptive evidence that abnormal press coverage around earnings announcements is positively associated with both the magnitude of the news in the earnings release and the level of investor demand for information about the firm. We find that abnormal press coverage is associated with the amount of firm disclosure and with abnormal returns and trading volume during the announcement period, but not with the magnitude of the earnings surprise. This finding suggests that the press views the stock market reaction to the earnings announcement as more "newsworthy" than the magnitude of the earnings surprise. Abnormal press coverage is also generally greater for large, high-growth firms with greater analyst following and number of employees, consistent with a consumer demand explanation for coverage.

Our paper contributes to the literature on information intermediaries by documenting how the business press influences firms' information environments. Our press coverage variables consistently exhibit incremental effects after controlling for the level of firm-initiated disclosure, and for the presence of other information intermediaries, such as analysts and institutional investors. Moreover, the press often has a larger impact on the information environment than the other intermediaries or firm-disclosures. These findings suggest that the business press fulfills a role as an important information intermediary.

The remainder of the paper is organized as follows. Section 2 discusses the roles of the press, reviews prior research, and presents our prediction. Section 3 provides a description of the sample and variable measurement. Section 4 presents results and section 5 concludes.

\section{Prior Literature and Empirical Predictions}


The business press plays an informational role around firms' earnings announcements in a number of ways. First, the press facilitates dissemination of the firm's earnings release. Multiple news wire services generally disseminate brief summaries of the key points of the earnings announcement shortly after the firm releases it. The press also alerts investors to upcoming scheduled firm disclosures, such as the time of the conference call or an appearance by the CEO on television. Second, the press packages information together from multiple sources. News wires frequently update their reports of the earnings announcement by adding analyst forecast information, price information, and management forecast information as it becomes available. The press also often puts together lists of "hot stocks" during the day. Finally, the press creates new information. In longer articles that often run in newspapers, reporters solicit quotes from management and analysts on the implications of the earnings release and interpret the management forecasts in the context of industry information. These multiple roles suggest the press' potential to increase information flow in the market and to reduce the level of information asymmetry across investors.

Recently, researchers have begun to investigate the role of the press in providing information to firms' investors, creditors, and other constituencies. Dyck and Zingales [2002] argue that, because the media is a vehicle through which information is aggregated and credibly communicated to the public, it can play a substantial role in reducing the costs of contracting. Dyck and Zingales [2002] and Miller [2006] argue that there is consumer demand for investigative reporting by the media. Zingales [2000] hypothesizes that readers rely on this reporting to form opinions when they believe the information provided is accurate and reliable. 
Much of the prior capital markets research on the press focuses on firm-initiated earnings announcement disclosures through press releases. ${ }^{1}$ For example, Francis, Schipper, and Vincent [2002] document that absolute stock returns around earnings announcements are related to the number and types of comments in firms' press releases. Van Buskirk [2006] finds that abnormal returns and volume around earnings announcements are greater when firms provide more words in their earnings press release. Further, he finds that a greater number of words in the press release is associated with lower bid-ask spreads and greater depth. Kross, Ro, and Schroeder [1990] document that the accuracy of analysts' forecasts is greater for firms with higher levels of coverage in the Wall Street Journal. Dyck and Zingales [2003] find that the market reaction to "street" earnings and GAAP earnings is stronger for the measure reported first in the press. Chan [2003] examines the predictability of stock returns following news headlines to draw inferences about investors' behavioral biases in responding to news events. Frankel and Li [2004] find an unexpected positive association between the number of news articles and various proxies for information asymmetry including the bid-ask spread. We extend these studies by examining separately the impact of firm-initiated disclosure from the role of the press in disseminating and interpreting such disclosure.

Our study is similar in spirit to research on the information intermediary role of analysts and institutional investors. Brennan and Subrahmanyam [1995] show that greater analyst coverage leads to smaller adverse selection costs and Yohn [1998] finds that greater analyst following is related to smaller bid-ask spreads around earnings announcements, consistent with analysts providing information that reduces information asymmetry. El-Gazzar [1998] finds that

\footnotetext{
${ }^{1}$ Another stream of research on the business press focuses on the press' role in facilitating corporate governance. Miller [2006] finds that the media fills a watchdog role in providing the public with information about accounting fraud. Dyck and Zingales [2002, 2004] provide evidence in an international setting that the media plays a role in corporate governance and influences firms' behavior. Joe, Louis, and Robinson [2009] and Core, Guay, and Larcker [2008] provide evidence on the role of the media in influencing CEO pay.
} 
price reactions around earnings announcements are smaller for firms with greater institutional ownership, consistent with institutional investors providing information through trading.

Similar to this work on analysts and institutional investors, we focus on the impact of the press on the information environment around earnings announcements. This setting ensures that every firm has an information event and allows us to use pre-announcement coverage as a control for "normal" levels of press coverage, firm disclosure, and stock market trading for the firm, which reduces the potential influence of correlated omitted variables.

Our main tests focus on the influence of the press on information asymmetry among investors. Diamond and Verrecchia [1991] show that more informative disclosures reduce the information advantage of privately informed traders, thereby reducing information asymmetry. The intuition is that information disclosures substitute for private information gathering and, therefore, lower information asymmetry. In our setting, if traders anticipate greater press coverage for a firm, they will see less advantage to gathering similar information. Moreover, if press coverage disseminates information to a broad group of traders who would not otherwise have the information, it will reduce the information advantage of the informed traders, thereby lowering adverse selection and information asymmetry. ${ }^{2}$ Because earnings announcements contain a predictable and extensive news release by the firm and cover a short-window, we expect that timely and broad dissemination of information and the packaging of information from multiple sources by the press will have a bigger impact on information asymmetry than the provision of new reporter-generated information. Following Lee, Mucklow and Ready [1993],

\footnotetext{
2 Alternatively, Kim and Verrecchia [1994] provide a model in which greater firm disclosure increases information asymmetry by allowing investors to differentially exploit their advantages in processing information during a short window. In this case, press coverage around the earnings announcement could exacerbate adverse selection and increase information asymmetry. However, it is likely that this effect is more pronounced in the presence of sophisticated market participants that possess idiosyncratic private information. In a sensitivity analysis discussed in Section 4.4, we find no evidence that the role of the press differs based on the level of institutional ownership.
} 
we use bid-ask spreads and depth to capture the price and quantity dimensions of information asymmetry. We predict that greater press coverage of the earnings announcement, especially through broader dissemination and more packaging of information, lowers bid-ask spreads and increases depths during the earnings announcement period.

\section{Sample Selection and Variable Measurement}

\subsection{SAMPLE SELECTION}

We obtain data on press articles between 1993 and 2004 from the Factiva database. We use the Factiva indexing codes to find all articles for the firm. Because of the high costs of handcollecting Factiva data, we limit our sample to a set of firms for which information asymmetry is likely to be an important issue and for which we expect significant cross-sectional variation in press coverage. First, we restrict our sample to NASDAQ firms, which are generally smaller and less followed by analysts than NYSE firms. ${ }^{3}$ Second, we require that firms be publicly traded during 1998. We select this date because intensive Factiva coverage begins around 1993, providing us with six years of potential coverage before and after 1998.

Next, we require that the sample firms have the necessary CRSP and Compustat data, as well as at least one quarterly earnings announcement date on Compustat in 1998. We then restrict the sample to mid-sized NASDAQ firms to eliminate firms with extremely high and extremely low press coverage. We rank the firms by market value on December 31, 1998 and eliminate the largest and smallest $20 \%$ of the distribution. To concentrate on firms with high expected information asymmetry, we rank the firms based on their market-to-book assets ratio (as a proxy for growth opportunities and information asymmetry), and select the $50 \%$ of the

\footnotetext{
${ }^{3}$ Additionally, restricting our sample to one exchange removes any effects of exchange listing on dependent variables such as spread and depth (see Van Buskirk [2006]).
} 
sample with the highest market-to-book assets ratios. For this sample, we collect Trade and Quote (TAQ) data, which we use to measure bid-ask spreads and market depths.

Finally, we merge the Factiva data with the CRSP, Compustat, and TAQ data. We match the articles' publication dates with trading dates, either in the firms' earnings announcement windows or in pre-earnings announcement windows. When an article occurs on a non-trading day (Saturday, Sunday, or holiday), we assign it to the next trading day. Our final sample consists of 600,478 press articles for 27,987 firm-quarter observations, representing 1,182 firms.

\subsection{INFORMATION ASYMMETRY MEASURES}

We examine the effect of the press on firms' information environments using bid-ask spreads and market depths during the earnings announcement period. We expect spreads and depths to vary across firms for economic reasons other than press coverage. Thus, we use the firm as its own control and compute abnormal values of spreads and depths during the earnings announcement event period. We define the EVENT period as the three trading days around the earnings announcement date; i.e., days -1 to $+1 .^{4}$ We define the $P R E$ period as the trading days starting two days after the previous earnings announcement through two days before the current announcement. When the previous announcement date is missing, we set the $P R E$ period to be 62 trading days prior to the EVENT period.

We measure abnormal bid-ask spread $\left(A B N \_S P R E A D\right)$ as the EVENT period average daily percent spread minus the $P R E$ period average daily percent spread. Daily percent spread is the daily average of each quote's spread, calculated as the difference between an offer price and a bid price divided by the midpoint of the offer and bid price (and multiplied by 100 ). ${ }^{5}$ We

\footnotetext{
${ }^{4}$ We also estimated all of our analyses using a five-day window around the earnings announcement and found virtually identical results for our press coverage variables.

${ }^{5}$ We use quotes with a positive spread between 9:30 am and 4:00pm, and remove quotes with spreads higher than $90 \%$ of the mid-point price. Depths are calculated with the same quotes used to calculate spreads.
} 
measure abnormal depth $\left(A B N \_D E P T H\right)$ as the log of the EVENT period average daily depth minus the log of the PRE period average daily depth. Daily depth is the daily average of each quote's depth, calculated as the sum of the dollar offer size and the dollar bid size.

\subsection{BUSINESS PRESS COVERAGE MEASURES}

The Factiva database contains both firm-initiated disclosures and press-initiated articles. We attempt to identify firm-initiated news releases and use them to control for the effect of firminitiated disclosure on the information environment. Similar to Bushee and Miller [2007] and Core et al. [2008], we assume that all articles carried on press release wires (e.g., PR Newswire, FD Newswire, and Business Wire) are firm-initiated disclosures. ${ }^{6}$ All other articles are considered press-initiated because news wires such as Reuters, Dow Jones, and the AP, as well as traditional publications, exercise editorial control over their content.

We proxy for the amount of firm-initiated disclosure (FIRMDISC) using the daily maximum word counts of press release articles. Because conference call transcripts often repeat the entire text of the earnings announcement press release, using the daily maximum word count reduces the chance that we double-count firm disclosure. When there is no press release wire available on an earnings announcement day, we consider the maximum word count article to represent the firm-initiated disclosure on that day, instead of press-initiated coverage. We compute abnormal firm disclosure (ABN_FIRMDISC) during the EVENT period using the percentage change from the PRE period: ABN_FIRMDISC $=\log \left(\left(1+\right.\right.$ FIRMDISC $\left._{\text {EVENT }}\right) /(1+$ FIRMDISC $\left.{ }_{P R E}\right)$.

We examine four aspects of press-initiated coverage to capture the amount and type of information the press provides, as well as the breadth of dissemination of the information. First,

\footnotetext{
${ }^{6}$ Some articles on the press release wires are not firm-initiated (e.g., an investor relations firm announcing that it has been retained by the firm as a client). However, because we proxy for the level of firm-initiated disclosure using the maximum word count press release, such press releases should have little effect on our proxy.
} 
as a general proxy for the total amount of information provided by the press, we examine the average of the daily sum of word counts $(W C)$ of press-initiated articles. ${ }^{7}$ Second, as a measure of the breadth of dissemination of information by the press, we examine the average of the daily counts of unique press sources $(S R C)$ that cover a firm. Third, to proxy for how much additional information the press packages together in its coverage, we use Factiva codes for the different topics included in the articles (ADDINFO), defined as the sum of the number of Factiva codes for the additional information (e.g., governance, product markets, legal issues, forecasts, analyst recommendations, etc.), divided by the period length. Fourth, to proxy for the degree to which the press creates new information, we use Factiva codes for whether the reporter has added his or her own analysis to the press articles (ANALYSIS), defined as the sum of the number of articles that have author by-lines and the sum of the number of Factiva codes for analysis, opinion, editorial content, detailed content, or interviews, divided by the period length. For each of these press variables (PRESS), we compute press activity (ABN_PRESS) during the EVENT period using the percentage change from the PRE period: $A B N \_P R E S S=\log \left(\left(1+P R E S S_{E V E N T}\right) /(1+\right.$ PRESS PRE)). Thus, we examine four measures of abnormal press coverage: $A B N \_W C$, $A B N \_S R C, A B N \_A D D I N F O$, and $A B N \_A N A L Y S I S$.

\subsection{CONTROL VARIABLES}

We control for the information content of the earnings announcement using a number of measures. First, we include the absolute value of the earnings surprise (ABS_ESURP), computed as: (1) the forecast error from the most recent $\mathrm{I} / \mathrm{B} / \mathrm{E} / \mathrm{S}$ consensus forecast prior to the announcement, if available; (2) the forecast error from the most recent First Call consensus forecast prior to the announcement, if available when the $\mathrm{I} / \mathrm{B} / \mathrm{E} / \mathrm{S}$ forecast is missing; or (3) the

\footnotetext{
${ }^{7}$ The amount of information can also be proxied by the number of articles. This measure is highly correlated with the word count $(r=0.87)$, and we find very similar results using the number of articles.
} 
seasonal random walk earnings surprise if the firm is not covered by either I/B/E/S or First Call. ${ }^{8}$ The earnings surprise is divided by the price at the end of the prior year's fiscal quarter. Next, we control for the stock return and volume reaction to the earnings announcement. We measure the absolute abnormal return $\left(A B S \_A B N \_R E T\right)$ as the absolute value of the difference between a firm's cumulative return and the cumulative equal-weighted market return during the three-day EVENT period. We measure abnormal trading volume $\left(A B N \_T U R N\right)$ as the EVENT period market-adjusted share turnover minus the $P R E$ period market-adjusted turnover, where turnover is the average daily dollar volume deflated by the market capitalization. ${ }^{9}$

We also control for a number of firm and industry characteristics that prior work shows to be associated with a firm's information environment. We include firm size (LNMV), defined as $\log$ of the market value of equity on the quarter-end date, analyst following (LNANALYST), measured as the log of one plus the number of analysts, and the percentage of institutional ownership (INST_HOLD). LNANALYST and INST_HOLD are measured at the most recent available date prior to the announcement. We control for growth opportunities using the book-tomarket assets ratio $(B T M)$. We also include the prior quarter stock-return volatility (Qt1_VOLAT), defined as the annualized standard deviation of the daily stock returns, and the market-adjusted share turnover in the prior quarter $\left(Q t 1 \_T U R N\right)$.

Next, we proxy for the firm-specific demand for press coverage from two major stakeholder groups by including LNEMPLOYEE (LNOWN), defined as the log of one plus the fiscal year-end number of employees (shareholders). We include the log of quarter-end stock price $(L N P R C)$ as an additional control for spreads and depths. Finally, we include $Q t 1 \_D E P T H$

\footnotetext{
${ }^{8}$ We use I/B/E/S for $55 \%$ of the observations, First Call for $7 \%$, and the seasonal random walk for $38 \%$. We estimated all of our analyses using only the seasonal random walk error and the results were virtually identical.

9 Measuring "trading volume" as turnover is common in the literature (see, e.g., Chae [2005]). We also estimated our results using undeflated dollar volume and logged dollar volume, and found similar results.
} 
(Qt1_SPREAD), defined as the prior quarter average of daily depth (spread), as a control in the spread (depth) regression. The latter variables control for the fact that market makers can protect themselves against information asymmetry by increasing spreads or reducing depths, and they can offset a change in spreads with a change in depths in the opposite direction (Yohn [1998]).

\section{Descriptive Statistics and Results}

\subsection{DESCRIPTIVE STATISTICS}

Table 1 provides descriptive statistics for the variables used in our analysis. First, we report descriptive statistics on the abnormal press coverage and firm disclosure variables. In all but one case, the mean and median abnormal press variables are positive, indicating that the press provides deeper coverage, more analysis, and greater dissemination around earnings announcements. The one exception is the negative median value for $A B N \_A D D I N F O$, which suggests that there is a narrower range of information provided in press articles during earnings announcement windows for the median firm. The mean and median values of abnormal firm disclosure are positive and large in magnitude, reflecting the fact that firms' earnings-related press releases often include summary financial statements and/or complete transcripts of conference calls.

Table 1 also shows that the mean abnormal percent spread is positive (0.024) and the mean abnormal depth is negative (-0.048), suggesting that on average the earnings announcement does not significantly lower information asymmetry. Next, the table presents the control variables. Not surprisingly, the mean and median abnormal stock return and volume measures are positive, indicating that stock returns typically respond to earnings announcements, and that a higher level of trading activity exists during the earnings announcement window. As expected based on our sample selection criteria, the sample firms tend to be mid-sized firms; the 
mean market value and price per share are $\$ 170$ million and $\$ 11.30$, respectively. The firms are also generally not widely-followed by analysts and institutional investors; the mean number of analysts is 2.4 and the mean percentage of institutional ownership is $29 \%$, which compares to 5.3 and 39\%, respectively, for Walther's [1997] broader sample of firms. Thus, these firms likely have weak public information environments and significant information asymmetries among investors, providing a powerful setting to examine the role of the press.

Pearson univariate correlation analyses show that the abnormal word count and abnormal source variables are highly correlated with each other $(\mathrm{r}=0.74)$, suggesting that it may be difficult to separate a dissemination effect from a quantity effect (not tabled). ABN_ADDINFO and $A B N \_A N A L Y S I S$ are significantly correlated with each other $(\mathrm{r}=0.35)$, as well as with the word count $(\mathrm{r}=0.42$ and 0.25 , respectively) and source variables $(\mathrm{r}=0.60$ and 0.41 , respectively). The word count and source variables are also positively correlated with the firminitiated disclosure variable, but to a lesser magnitude $(\mathrm{r}<0.38)$, suggesting that press coverage is not solely determined by the volume of firm disclosure. The press variables exhibit small correlations with firm size, analyst following, and institutional investors $(\mathrm{r}<0.22)$, indicating that press coverage around an earnings announcement is not merely proxying for some other aspect of firms' information environments.

\subsection{DETERMINANTS OF ABNORMAL PRESS COVERAGE}

The coverage decisions of the press are not exogenous, but rather are expected to be a function of their incentives to write articles about a given firm. The ultimate objective of the press is to maximize subscription and advertising revenues by attracting greater readership, which the press accomplishes through covering firms with greater consumer demand for information and by covering more "memorable" or newsworthy events (Miller [2006], Core, et 
al. [2008]). For journalists, monetary rewards tend to be secondary to non-monetary rewards such as fame and attention, which aligns their incentives with their organizations' goals (Fengler and Ruß-Mohl [2008]). To examine and control for these incentives in our setting, we provide descriptive evidence on the determinants of abnormal press coverage around earnings announcements. We regress each of the four proxies for press coverage on the control variables and on 48 industry indicator variables (Fama and French [1997]). We estimate regressions for each fiscal quarter in the sample period and report the mean coefficients across quarters, with significance tests based on the distribution of the quarterly regression coefficients (Fama and MacBeth [1973]), adjusted for autocorrelation using the Newey and West [1987] procedure with four lags.

Table 2 presents the results of these regressions. Press coverage around earnings announcements exhibits a consistent positive association with firm disclosure. Press coverage is also significantly positively associated with abnormal returns and trading volume during the announcement period, but only weakly associated with the magnitude of the earnings surprise. This finding suggests that the press views the magnitude of market reaction as more "newsworthy" than the magnitude of the earnings surprise. Also, this finding is consistent with press coverage having some influence of the return and volume reaction, but no influence on the size of the earnings surprise. Press coverage is also greater for firms with greater analyst following, number of employees, and, to a lesser extent, number of shareholders. Larger firms are covered by a greater number of sources and have more articles with additional information, but have fewer abnormal words of press coverage during the announcement period, which is likely due to a higher level of coverage in the $P R E$ period. For a similar reason, firms with high prior turnover have smaller abnormal word counts. Finally, high-growth firms (i.e., low BTM 
ratios) experience greater word count and dissemination than low-growth firms, but low-growth firms have more additional information included in their press coverage. Overall, the results suggest that abnormal press coverage is significantly related to both the magnitude of the news in the earnings release and the likely level of investor demand for information about the firm.

\subsection{RESULTS}

We examine the impact of press coverage on firms' information environments by estimating regressions of bid-ask spreads and market depths on the press coverage variables, firm-initiated disclosure proxies, control variables, and industry indicator variables. ${ }^{10}$ This relation has a likely causal link because, unlike a large initial price or volume reaction (which the press often cites in its coverage), it is difficult to identify clear incentives for the press to increase its coverage of firms with narrowing spreads or increasing depth (and we have not seen any anecdotal evidence of this). In addition, we report Hausman tests below that do not reject the hypothesis that the press coverage variables are exogenous in our regression models. We estimate regressions for each quarter and report the mean coefficients across quarters, with significance tests based on the distribution of the quarterly regression coefficients, adjusted for autocorrelation using the Newey and West [1987] procedure with four lags. Because a reduction in information asymmetry would reduce spreads and increase depths, we expect the coefficient on the press variables to be negative (positive) in the spread (depth) regression.

Table 3 reports the results of these regressions. Press coverage measured as the abnormal number of sources $\left(A B N \_S R C\right)$ is significantly negatively (positively) associated with abnormal spreads (depths). In terms of economic significance, a one standard deviation increase in the abnormal number of sources would reduce percent spreads by 0.11 , which is $3 \%$ of the

\footnotetext{
${ }^{10}$ We exclude number of employees (LNEMPLOYEE) from the controls used in the regressions because we are unaware of reasons to expect that this variable explains abnormal spreads or depth and because we use this variable as an instrument in sensitivity analyses that consider the potential endogeneity of press coverage.
} 
mean EVENT spread of $3.74 \% .{ }^{11}$ Further, a one standard deviation increase in the abnormal number of sources would increase abnormal depths by about $2 \%$. Interestingly, the amount of reporter-generated analysis $\left(A B N \_A N A L Y S I S\right)$ has an unexpected significant negative association with abnormal depth. This result suggests that, controlling for abnormal dissemination, more reporter-generated information increases information asymmetry. While this finding is consistent with the Kim and Verrecchia [1994] idea that new information disclosures can increase information asymmetry through the differential ability of investors to process the information in a short-window, it must be interpreted with caution due to the lack of significance of $A B N \_A N A L Y S I S$ in the spread regressions. Overall, our results suggest that the dissemination of information to a broad group of investors during an earnings announcement has a bigger impact on reducing information asymmetry than the quantity or quality of information provided by the press. $^{12}$

We also estimate the regressions in Table 3 with each of the press coverage variables included individually (not tabled). ${ }^{13}$ We find that abnormal word count $\left(A B N_{-} W C\right)$ and abnormal sources $\left(A B N \_S R C\right)$ are significantly negatively (positively) related to spreads (depths), whereas abnormal additional information and abnormal analysis are not significant.

\footnotetext{
${ }^{11}$ We also examine whether the level of spreads in the pre-announcement period is associated with the level of press coverage and find similar significant negative associations. Soltes [2009] finds similar results using total press coverage and average spreads over the year on a post-2001 sample that also includes NYSE/AMEX firms.

${ }^{12}$ The signs on the control variables in table 3 are consistent with prior research, and are similar if the press variables are excluded. Interestingly, firm disclosure has only a limited impact on changes in spreads and depth. This lack of significance may stem from a weak proxy for firm disclosure. We also consider a number of other proxies, including: the average daily word count, the average daily maximum word count from each unique source, the maximum word count of any article during the period, and the average number of unique sources. In untabulated tests, we include all five proxies in the regressions, and alternatively include a factor comprised of these variables. None of these alternative proxies affect the sign or significance of the firm disclosure or press variables.

${ }^{13}$ In Section 4.1, we report that some of the bivariate correlations among press variables are high. We compute variance inflation factors (VIF) for all of our regressions and none of the press variables have a VIF above 4, which is below the common benchmark of 10 for harmful multicollinearity.
} 
These results suggest that, while word counts alone can proxy for the influence of the press on information asymmetry, they are subsumed by a proxy for dissemination. ${ }^{14}$

\subsection{ADDITIONAL ANALYSES}

To provide additional evidence on the impact of the press on firms' information environments, we examine the influence of press coverage on small traders and block traders. Prior work suggests that small investors are more likely to trade when they receive direct access to information (Bushee, Matsumoto, and Miller [2003]). Thus, if the press is effective at disseminating information to a broad set of investors, we expect that changes in the number of small trades during the earnings announcement period will be positively related to abnormal press coverage, controlling for changes in overall trading volume. Prior work also suggests that large trades are sensitive to the level of bid-ask spreads and market depth (Hasbrouck [1991], Stoll and Schenzler [2006]). If abnormal press coverage reduces the potential adverse selection costs of block trades, we expect that it will increase the number of large trades executed during the earnings announcement window, again controlling for changes in overall trading volume

Using trade data from TAQ, we define small trades as trades with a dollar value less than $\$ 5,000$ and large trades as trades with a dollar value larger than $\$ 30,000$, using the largest roundlot size less than or equal to the given dollar threshold computed with the price at the beginning of the day (Bushee, et al. [2003]). We measure the abnormal number of small (large) trades as the difference between the event and control period sum of the daily number of small (large) trades, divided by the event period sum of the daily number of small (large) trades. We follow

\footnotetext{
${ }^{14}$ A potential concern is that press coverage variables are endogenously determined with spreads and depth. Thus, we perform Hausman tests of endogeneity. We identify the number of employees as an instrumental variable for press coverage. As shown in table 2, this variable is associated with press coverage, yet is unlikely to be related to spreads and depth (this lack of association is confirmed if we include it in the regressions). In untabulated tests, for each of the eight combinations of spread or depth and the individual press coverage variables, we find the residuals from the regression of each press coverage variable on the controls and the instruments are not significantly associated with abnormal spreads and depth, suggesting that press coverage is exogenous in the Table 3 regressions.
} 
Bushee et al. [2003] in using the three trading days before the event period as a control period. We estimate regressions of abnormal small and large trades during the announcement period on press coverage and control variables using the same methodology as in the spread and depth regressions (not tabled). We find that three measures of press coverage-abnormal word count, number of sources, and amount of additional information—are significantly positively related to changes in the number of small trades. Thus, both dissemination and quantity of information influence small trader activity. For block trades, abnormal word count and additional information are significantly positively related to changes in the number of large trades, suggesting that quantity of information is the main factor in facilitating block trades. Overall, we find that press coverage facilitates trading by both small and block traders during the earnings announcement, consistent with a press-induced improvement in the firms' information environment. ${ }^{15}$

\section{Conclusion}

This paper examines whether the business press serves as an information intermediary. The press fulfills multiple roles, including broad dissemination of information, packaging information from multiple sources, and creating new information through journalism practices. Through these activities, the press has the potential to influence the degree of information asymmetry across investors. We find that greater press coverage significantly reduces the degree of information asymmetry during earnings announcement periods in terms of both reduced bidask spreads and greater market depth, with the broad dissemination of information having a bigger impact than the quantity or quality of information provided by the press. These results are

\footnotetext{
${ }^{15}$ We also performed a number of additional sensitivity analysis. First, we interacted the press coverage variables with proxies for a firm's information environment (e.g., size, analyst following, institutional ownership) and with proxies for the news in the earnings announcement (e.g., direction and magnitude of earnings surprises and stock returns). We found no substantive difference in the interaction terms, suggesting that press coverage is generally important for our sample firms regardless of their information environments or earnings news. Second, we partitioned press coverage by whether it is provided in "major" sources or "non-major" sources (as classified by Factiva) and by whether it was provided by a press wire service or a non-wire service. In both cases, there were no substantive differences in results between these measures.
} 
robust to controlling for firm-initiated disclosures, the market reaction to the announcement, the presence of other information intermediaries, and other firm characteristics.

Our study is subject to a number of caveats. First, our results are based on a sample of mid-sized NASDAQ firms that are more likely to have weak public information environments. This sample provides a powerful setting to test for the effect of the press, but our results may not be generalizable to samples of large firms with rich information environment or small, neglected firms. Second, we focus our study around earnings announcement periods, which contain a predictable news release and cover a short-window. It is possible that the effect of the press could be different in less predictable contexts, such as a merger announcement or a change in management. Holding aside these caveats, we find strong and consistent evidence that the press is an independent information intermediary and an important factor in reducing information problems related to earnings announcements.

Our study suggests that, as Factiva data becomes more readily available, future work should attempt to incorporate measures of press coverage into studies examining changes in information asymmetry around earnings announcements. Moreover, future work could extend our findings to test for the relative importance of the press vis-à-vis other intermediaries around other major corporate events. Finally, the fact that the press has the potential to provide such as beneficial role in shaping firm's information environments motivates future work examining how corporate managers can act to improve the timeliness and breadth of dissemination of their disclosures by the press. 


\section{References}

BREnNAN, M., AND A. Subrahmanyam. "Investment Analysis and Price Formation in Securities Markets.” Journal of Financial Economics 38 (1995): 361-381.

Bushee, B.; D. Matsumoto; And G. Miller. "Open versus Closed Conference Calls: The Determinants and Effects of Broadening Access to Disclosure." Journal of Accounting \& Economics 34 (2003): 149-180.

BusheE, B., AND G. Miller. "Investor Relations, Firm Visibility, and Investor Following." Working paper, University of Pennsylvania, 2007.

CHAE, J. "Trading Volume, Information Asymmetry, and Timing Information." The Journal of Finance 60 (2005): 413-442.

ChAn, W. "Stock Price Reaction to News and No-News: Drift and Reversal after Headlines." Journal of Financial Economics 70 (2003): 223-260.

CORE, J.; W. GUAY; AND D. LARCKER. "The Power of the Pen and Executive Compensation." Journal of Financial Economics 88 (2008): 1-25.

DiAmOND, D., AND R. VERRECCHIA. "Disclosure, Liquidity, and the Cost of Capital." The Journal of Finance 46 (1991): 1325-1359.

DyCK, A., AND L. Zingales. "The Corporate Governance Role of the Media.” Working paper, Harvard University, 2002.

DyCK, A., AND L. Zingales. “The Media and Asset Prices.” Working paper, Harvard University, 2003.

DYCK, A., AND L. ZingALES. "Private Benefits of Control: An International Comparison." Journal of Finance 59 (2004): 537-600.

EL-GaZZAR, S. "Predisclosure Information and Institutional Ownership: A Cross-Sectional Examination of Market Revaluations during Earnings Announcement Periods.” The Accounting Review 73 (1998): 119-130.

FAMA, E., AND K. FRENCH. "Industry Costs of Equity.” Journal of Financial Economics 43 (1997):153-193.

FAMA, E., AND J. MACBETH. “Risk, Return, and Equilibrium: Empirical Tests.” Journal of Political Economy 81 (1973): 607-636.

FENGLER, S. AND S. RUß-MOHL. "Journalists and the information-attention markets: Towards an economic theory of journalism" Journalism (2008): 667-690. 
FRANCIS, J.; K. SCHIPPER; AND L. VINCENT. "Expanded Disclosures and the Increased Usefulness of Earnings Announcements.” The Accounting Review 77 (2002): 515-547.

FRANKEL, R., AND X. LI. "Characteristics of a Firm's Information Environment and the Information Asymmetry between Outsiders and Insiders." Journal of Accounting \& Economics 37 (2004): 229-259.

HASBROUCK, J. "The Summary Informativeness of Stock Trades: An Econometric Analysis.” The Review of Financial Studies 4 (1991): 571-594.

KIM, O., AND R. VERRECCHIA. "Market Liquidity and Volume around Earnings Announcements." Journal of Accounting \& Economics 17 (1994): 41-68.

Kross, W.; B. Ro; AND D. SchroEDER. "Earnings Expectations: The Analysts' Information Advantage." The Accounting Review 65 (1990): 461-477.

LEE, C.; B. MucKLOW; AND M. READY. "Spreads, Depths, and the Impact of Earnings Information: An Intraday Analysis.” The Review of Financial Studies 6 (1993): 345-364.

JoE, J.; H. LOUIS; AND D. Robinson. “Managers' and Investors' Responses to Media Exposure of Board Ineffectiveness." Journal of Financial and Quantitative Analysis 44 (2009): 579605.

MILLER, G. "The Press as a Watchdog for Accounting Fraud." Journal of Accounting Research 44 (2006): 1001-1033.

NewEY, W., AND K. WeST. "A Simple, Positive Semi-Definite Heteroscedasticity and Autocorrelation Consistent Covariance Matrix.” Econometrica 55 (1987): 703-708.

Soltes, E., "News Dissemination and the Impact of the Business Press" Working paper, University of Chicago Booth School of Business, 2009.

StOll, H., AND C. SCHENZLER. "Trades Outside the Quotes: Reporting Delay, Trading Option, or Trade Size?" Journal of Financial Economics 79 (2006): 615-653.

VAN BuskiRK, A. "Capital Market Effects of More Frequent Disclosure.” Working paper, University of Chicago Booth School of Business, 2006.

WALTHER, B. "Investor Sophistication and Market Earnings Expectations." Journal of Accounting Research 35 (1997): 157-179.

YoHn, T. "Information Asymmetry Around Earnings Announcements." Review of Quantitative Finance and Accounting 11 (1998): 165-182.

ZINGALES, L. "In Search of New Foundations." The Journal of Finance 55 (2000): 1623-1653. 
TABLE 1

Descriptive Statistics

\begin{tabular}{|c|c|c|c|}
\hline Variable & Mean & Median & Std Dev \\
\hline ABN_WC & 0.563 & 0.839 & 1.974 \\
\hline ABN_SRC & 0.282 & 0.257 & 0.294 \\
\hline ABN_ADDINFO & 0.060 & -0.026 & 0.402 \\
\hline ABN_ANALYSIS & 0.029 & 0.000 & 0.146 \\
\hline ABN_FIRMDISC & 2.439 & 2.612 & 2.031 \\
\hline ABN_SPREAD & 0.024 & -0.045 & 1.638 \\
\hline ABN_DEPTH & -0.048 & -0.029 & 0.342 \\
\hline ABS_ABN_RET & 0.077 & 0.054 & 0.077 \\
\hline ABN_TURN & 0.003 & 0.000 & 0.013 \\
\hline ABS_ESURP & 0.052 & 0.004 & 0.250 \\
\hline MV & 169.753 & 90.384 & 251.612 \\
\hline BTM & 0.551 & 0.506 & 0.322 \\
\hline ANALYST & 2.440 & 2.000 & 2.705 \\
\hline INST_HOLD & 0.294 & 0.235 & 0.240 \\
\hline EMPLOYEYE & 0.793 & 0.286 & 1.593 \\
\hline OWN & 2.494 & 0.858 & 4.227 \\
\hline PRC & 11.295 & 8.063 & 10.720 \\
\hline Qt1_VOLAT & 0.784 & 0.705 & 0.369 \\
\hline Qt1_TURN & 0.001 & -0.001 & 0.009 \\
\hline Qt1_SPREAD & 3.736 & 2.932 & 2.951 \\
\hline Qt1_DEPTH & 17.041 & 13.256 & 13.597 \\
\hline
\end{tabular}

The number of observations for each of the variables is 27,987 . The earnings announcement (EVENT) period is from -1 to +1 trading days from the earnings announcement date (Compustat $R D Q E$ ). The pre-earnings announcement $(P R E)$ period includes trading days between two EVENT periods or up to 62 trading days prior to the $E V E N T$ period when the previous quarter's $R D Q E$ is not available. All press variables are from news articles from the Factiva database. WC is the period sum of word counts for press-initiated articles divided by the period length. SRC is the sum of the daily numbers of unique press sources during the period divided by the period length. ADDINFO is the period count of Factiva news subject codes which we identify as capital market, governance, innovation, legal issues, corporate changes, management issues, marketing, company profile, return, sales, analyst comment and recommendations, or earnings projections, divided by the period length. ANALYSIS is the period sum of the number of articles that have author by-lines and the count of Factiva news subject codes which we identify as analysis, opinions, editorials, detailed information, or interviews, divided by the period length. For each of these press variables (PRESS), we compute press activity (ABN_PRESS) during the EVENT period using the percentage change from the PRE period: ABN_PRESS $=\log ((1+P R E S S$ $\left.E_{E V E N T}\right) /\left(1+\right.$ PRESS $\left.\left._{P R E}\right)\right)$. FIRMDISC is the period sum of the daily maximum firm-initiated article word counts divided by the period length. ABN_FIRMDISC $=\log \left(\left(1+F I R M D I S C_{E V E N T}\right) /\left(1+F I R M D I S C_{P R E}\right)\right)$. SPREAD is the period average of daily spreads multiplied by 100 , where the daily spread is the daily average of each quote's spread. Each quote's spread is calculated as the offer price minus the bid price divided by the midpoint of the offer price and the bid price. ABN_SPREAD=SPREAD ${ }_{E V E N T}-S P R E A D_{P R E}$. DEPTH is the period average of daily depths, where the daily depth is the daily average of each quote's depth. Each quote's depth is calculated as (offer size*offer price+ bid size*bid price), where the offer size and bid size are multiplied by 100 . ABN_DEPTH $=\log \left(D E P T H_{E V E N T} / D E P T H_{P R E}\right)$. ABS_ABN_RET is the absolute abnormal return of the EVENT period. TURNOVER is the average of daily CRSP trading dollar volumes divided by the average market value of shares outstanding. The market TURNOVER is the TURNOVER calculated with all stocks in the NASDAQ. ABN_TURN is (the EVENT period TURNOVER minus EVENT period market TURNOVER) minus (the PRE period TURNOVER minus PRE period market TURNOVER). ABS_ESURP is the absolute value of the earnings forecast error deflated by the price at the end of quarter t-4. Forecast error is defined as: (1) actual EPS minus the most recent I/B/E/S consensus forecast prior to the announcement, if available; (2) actual EPS minus the most recent First Call consensus forecast prior to the announcement, if available when the $\mathrm{I} / \mathrm{B} / \mathrm{E} / \mathrm{S}$ forecast is missing; or (3) the seasonal random walk earnings surprise, defined as $\mathrm{EPS}_{\mathrm{t}}$ minus $\mathrm{EPS}_{\mathrm{t}-4}$, if the firm is not covered by either $\mathrm{I} / \mathrm{B} / \mathrm{E} / \mathrm{S}$ or First Call. LNMV is the log of the CRSP market value (in thousands) on the fiscal quarter end date. The figures tabulated (MV) are raw values (in millions) before taking the log. BTM is the Book-ToMarket assets ratio (Compustat \#44/(Compustat \#44-Compustat \#59 + Market Value))) on the fiscal quarter end date. LNANALYST is the log of 1 plus the number of analysts following counted from $\mathrm{I} / \mathrm{B} / \mathrm{E} / \mathrm{S}$ on the most recent date available in three months prior to the earnings announcement. The figures tabulated (ANALYST) are raw values before taking the log. INST_HOLD is the percentage of institutional ownership from Thomson Financial Spectrum on the most recent date available in three months prior to the earnings announcement. LNEMPLOYEE is the log of 1 plus the number of employees (Compustat Annual \#29). LNOWN is the log of 1 plus shareholders (Compustat Annual \#100). The figures tabulated (EMPLOYEE and OWN) are raw values (in millions) before taking the $\log$. LNPRC is the log of the fiscal quarter end price. The figures tabulated (PRC) are raw values before taking the log. Qt1_TURN is the quarter t-1's TURNOVER minus quarter t1's market TURNOVER. Qt1_VOLAT is the quarter t-1's return volatility calculated as the standard deviation of the log of 1 plus daily return, multiplied by $\sqrt{252}$. Qt1_SPREAD is the quarter t-1 average of daily spreads multiplied by 100. Qt1_DEPTH is the log of the quarter t-1 average of daily depths. The figures tabulated (Qt1_DEPTH) are raw values (in thousands) before taking the log. All variables are winsorized at $1 \%$. 
TABLE 2

Determinants of Abnormal Press Coverage

\begin{tabular}{|c|c|c|c|c|}
\hline & $\begin{array}{c}\text { ABN_WC } \\
1\end{array}$ & $\underset{2}{\text { ABN_SRC }}$ & $\begin{array}{c}\text { ABN_ADDINFO } \\
3\end{array}$ & $\begin{array}{c}\text { ABN_ANALYSIS } \\
4\end{array}$ \\
\hline INTERCEPT & 0.625 & -0.056 & $-0.221 * * *$ & -0.042 \\
\hline ABN_FIRMDISC & $0.338 * * *$ & $0.047 * * *$ & $0.027 * * *$ & $0.004 * * *$ \\
\hline ABS_ABN_RET & $0.796 * * *$ & $0.184 * * *$ & $0.399 * * *$ & $0.035 * * *$ \\
\hline ABN_TURN & $14.027 * * *$ & $3.386 * * *$ & $6.129 * * *$ & $1.445 * * *$ \\
\hline ABS_ESURP & $-0.299 *$ & -0.006 & 0.004 & $0.016 *$ \\
\hline LNMV & $-0.090 *$ & $0.013 * * *$ & $0.007 *$ & 0.004 \\
\hline ВТМ & $-0.148 * *$ & $-0.018 *$ & $0.024 * *$ & -0.004 \\
\hline LNANALYST & 0.069 & $0.029 * * *$ & $0.023 * *$ & $0.005 * * *$ \\
\hline INST_HOLD & -0.006 & -0.020 & 0.021 & -0.004 \\
\hline LNEMPLOYEE & $0.157 * * *$ & $0.036 * * *$ & $0.023 * * *$ & $0.018 * * *$ \\
\hline LNOWN & -0.028 & 0.004 & $0.005 * *$ & $0.004 * *$ \\
\hline Qt1_TURN & $-10.767 * * *$ & -0.474 & -0.706 & 0.411 \\
\hline Qt1_VOLAT & -0.015 & -0.005 & -0.005 & -0.010 \\
\hline Adjusted $R^{2}$ & 0.223 & 0.254 & 0.094 & 0.044 \\
\hline
\end{tabular}

This table provides regressions of press coverage on determinants of press coverage variables and the (untabulated) Fama-French 48 industry classification dummy variables. The number of observations in each of these regressions is 27,987 . We estimate 48 quarterly regressions and report the mean coefficients. Fama and MacBeth (1973) standard errors are corrected for autocorrelation using the Newey and West (1987) adjustment with four lags. WC is the period sum of word counts for press-initiated articles divided by the period length. SRC is the sum of the daily numbers of unique press sources during the period divided by the period length. ADDINFO is the period count of Factiva news subject codes which we identify as capital market, governance, innovation, legal issues, corporate changes, management issues, marketing, company profile, return, sales, analyst comment and recommendations, or earnings projections, divided by the period length. ANALYSIS is the period sum of the number of articles that have author by-lines and the count of Factiva news subject codes which we identify as analysis, opinions, editorials, detailed information, or interviews, divided by the period length. For each of these press variables (PRESS), we compute press activity (ABN_PRESS) during the EVENT period using the percentage change from the PRE period: ABN_PRESS $=\log \left(\left(1+P R E S S_{\text {EVENT }}\right) /(1+P R E S S\right.$ $P R E)$ ). FIRMDISC is the period sum of the daily maximum firm-initiated article word counts divided by the period length. ABN_ FIRMDISC $=$ $\log \left(\left(1+F I R M D I S C_{E V E N T}\right) /\left(1+F I R M D I S C_{P R E}\right)\right)$. ABS_ABN_RET is the absolute abnormal return of the EVENT period. TURNOVER is the average of daily CRSP trading dollar volumes divided by the average market value of shares outstanding. The market TURNOVER is the TURNOVER calculated with all stocks in the NASDAQ. ABN_TURN is (the EVENT period TURNOVER minus EVENT period market TURNOVER) minus (the PRE period TURNOVER minus PRE period market TURNOVER). ABS_ESURP is the absolute value of the earnings forecast error deflated by the price at the end of quarter t-4. Forecast error is defined as: (1) actual EPS minus the most recent I/B/E/S consensus forecast prior to the announcement, if available; (2) actual EPS minus the most recent First Call consensus forecast prior to the announcement, if available when the $\mathrm{I} / \mathrm{B} / \mathrm{E} / \mathrm{S}$ forecast is missing; or (3) the seasonal random walk earnings surprise, defined as $\mathrm{EPS}_{\mathrm{t}}$ minus $\mathrm{EPS}_{\mathrm{t}-4}$, if the firm is not covered by either I/B/E/S or First Call. LNMV is the log of the CRSP market value (in thousands) on the fiscal quarter end date. BTM is the Book-To-Market assets ratio (Compustat \#44/(Compustat \#44-Compustat \#59 + Market Value))) on the fiscal quarter end date. LNANALYST is the log of 1 plus the number of analysts following counted from $\mathrm{I} / \mathrm{B} / \mathrm{E} / \mathrm{S}$ on the most recent date available in three months prior to the earnings announcement. INST_HOLD is the percentage of institutional ownership from Thomson Financial Spectrum on the most recent date available in three months prior to the earnings announcement. LNEMPLOYEE is the log of 1 plus the number of employees (Compustat Annual \#29). LNOWN is the log of 1 plus shareholders (Compustat Annual \#100). LNPRC is the log of the fiscal quarter end price. Qt1_TURN is the quarter t-1's TURNOVER minus quarter t-1's market TURNOVER. Qt1_VOLAT is the quarter t-1's return volatility calculated as the standard deviation of the $\log$ of 1 plus daily return, multiplied by $\sqrt{252}$. All variables are winsorized at $1 \%$. 
TABLE 3

Regressions of Abnormal Bid-Ask Spreads and Abnormal Depth on Press Coverage Variables and Control Variables

\begin{tabular}{|c|c|c|c|c|}
\hline & $\begin{array}{c}\text { Predicted } \\
\text { Sign }\end{array}$ & ABN_SPREAD & $\begin{array}{c}\text { Predicted } \\
\text { Sign } \\
\end{array}$ & ABN_DEPTH \\
\hline INTERCEPT & & -0.011 & & $-0.185 * *$ \\
\hline ABN_WC & - & 0.012 & + & -0.003 \\
\hline ABN_SRC & - & $-0.361 * * *$ & + & $0.068 * * *$ \\
\hline ABN_ADDINFO & - & 0.042 & + & 0.001 \\
\hline ABN_ANALYSIS & - & 0.104 & + & $-0.068 * * *$ \\
\hline ABN_FIRMDISC & & $0.012 *$ & & -0.001 \\
\hline ABS_ABN_RET & & $2.284 * * *$ & & $-0.248 * * *$ \\
\hline ABN_TURN & & $-21.424 * * *$ & & $5.336 * * *$ \\
\hline ABS_ESURP & & 0.226 & & -0.011 \\
\hline LNMV & & $-0.037 *$ & & 0.010 \\
\hline BTM & & 0.010 & & -0.008 \\
\hline LNANALYST & & 0.009 & & -0.004 \\
\hline INST_HOLD & & 0.024 & & -0.009 \\
\hline LNOW̄N & & -0.012 & & 0.000 \\
\hline LNPRC & & $-0.073 *$ & & -0.002 \\
\hline Qt1_TURN & & $15.910 * * *$ & & $-3.181 * * *$ \\
\hline Qt1_VOLAT & & $-0.497 * * *$ & & 0.013 \\
\hline Qt1_DEPTH & & $0.105 *$ & & \\
\hline Qt1_SPREAD & & & & $0.003 *$ \\
\hline Adjusted $R^{2}$ & & 0.069 & & 0.076 \\
\hline
\end{tabular}

This table provides regressions of abnormal bid-ask spreads and abnormal depth on press coverage and control variables, including the (untabulated) Fama-French 48 industry classification dummy variables. The number of observations in each regression is 27,987 . We estimate 48 quarterly regressions and report the mean coefficients. Fama and MacBeth (1973) standard errors are corrected for autocorrelation using the Newey and West (1987) adjustment with four lags. WC is the period sum of word counts for press-initiated articles divided by the period length. SRC is the sum of the daily numbers of unique press sources during the period divided by the period length. ADDINFO is the period count of Factiva news subject codes which we identify as capital market, governance, innovation, legal issues, corporate changes, management issues, marketing, company profile, return, sales, analyst comment and recommendations, or earnings projections, divided by the period length. ANALYSIS is the period sum of the number of articles that have author by-lines and the count of Factiva news subject codes which we identify as analysis, opinions, editorials, detailed information, or interviews, divided by the period length. For each of these press variables (PRESS), we compute press activity $\left(A B N \_P R E S S\right)$ during the EVENT period using the percentage change from the PRE period: $A B N \_P R E S S=\log ((1+$ PRESS $\left._{\text {EVENT }}\right) /\left(1+\right.$ PRESS $\left.\left._{P R E}\right)\right)$. FIRMDISC is the period sum of the daily maximum firm-initiated article word counts divided by the period length. ABN_FIRMDISC $=\log \left(\left(1+F I R M D I S C_{E V E N T}\right) /\left(1+F I R M D I S C_{P R E}\right)\right)$. SPREAD is the period average of daily spreads multiplied by 100 , where the daily spread is the daily average of each quote's spread. Each quote's spread is calculated as the offer price minus the bid price divided by the midpoint of the offer price and the bid price. ABN_SPREAD=SPREAD ${ }_{E V E N T}-S P R E A D_{P R E}$. DEPTH is the period average of daily depths, where the daily depth is the daily average of each quote's depth. Each quote's depth is calculated as (offer size*offer price+ bid size*bid price), where the offer size and bid size are multiplied by 100 . ABN_DEPTH $=\log \left(D E P T H_{\text {EVENT }} / D E P T H_{P R E}\right)$. ABS_ABN_RET is the absolute abnormal return of the EVENT period. TURNOVER is the average of daily CRSP trading dollar volumes divided by the average market value of shares outstanding. The market TURNOVER is the TURNOVER calculated with all stocks in the NASDAQ. ABN_TURN is (the EVENT period TURNOVER minus EVENT period market TURNOVER) minus (the PRE period TURNOVER minus PRE period market TURNOVER). ABS_ESURP is the absolute value of the earnings forecast error deflated by the price at the end of quarter t -4 . Forecast error is defined as: (1) actual EPS minus the most recent I/B/E/S consensus forecast prior to the announcement, if available; (2) actual EPS minus the most recent First Call consensus forecast prior to the announcement, if available when the $\mathrm{I} / \mathrm{B} / \mathrm{E} / \mathrm{S}$ forecast is missing; or (3) the seasonal random walk earnings surprise, defined as $\mathrm{EPS}_{\mathrm{t}}$ minus EPS $\mathrm{t}_{\mathrm{t}-4}$, if the firm is not covered by either I/B/E/S or First Call. LNMV is the log of the CRSP market value (in thousands) on the fiscal quarter end date. BTM is the Book-To-Market assets ratio (Compustat \#44/(Compustat \#44-Compustat \#59 + Market Value))) on the fiscal quarter end date. LNANALYST is the log of 1 plus the number of analysts following counted from $\mathrm{I} / \mathrm{B} / \mathrm{E} / \mathrm{S}$ on the most recent date available in three months prior to the earnings announcement. INST_HOLD is the percentage of institutional ownership from Thomson Financial Spectrum on the most recent date available in three months prior to the earnings announcement. LNOWN is the log of 1 plus shareholders (Compustat Annual \#100). LNPRC is the log of the fiscal quarter end price. Qt1_TURN is the quarter t-1's TURNOVER minus quarter t-1's market TURNOVER. Qt1_VOLAT is the quarter t-1's return volatility calculated as the standard deviation of the log of 1 plus daily return, multiplied by $\sqrt{252}$. Qt1_SPREAD is the quarter t-1 average of daily spreads multiplied by 100. Qt1_DEPTH is the log of the quarter t-1 average of daily depths. All variables are winsorized at $1 \%$. 